\title{
Unitas Multiplex. Biological architectures of consciousness
}

\author{
Nelson Mauro Maldonato, Benedetta Muzii, Mario Bottone, Raffaele Sperandeo, \\ Donatella Di Corrado, Grazia Isabella Continisio, Teresa Rea, Anna Esposito
}

\begin{abstract}
The so-called Posthuman question - the birth of organisms generated by the encounter of biological and artificial entities (humanoid robots, cyborgs and so on) - is now on the agenda of science and, more generally, of contemporary society. This is an issue of enormous importance, which not only poses ethical questions but also, and above all, methodological questions about how it will be achieved on a scientific plane. How such entities will be born and what their functions will be? For example, what kind of consciousness will they be equipped with, in view of the function of consciousness for distinguishing the Self from others, which is the foundation of the interactive life of relationships? Many scholars believe that rapid technological progress will lead to the emergence of organisms that will simulate the functions of the mind, learn from their experiences, decode real-world information, and plan their actions and choices based on their own values elaborated from vast amounts of data and metadata. In the not-too-distant future, it is believed that these entities will acquire awareness and, consequently, decisional freedom, and perhaps even their own unique morals. In this paper, we try to show that the path towards this goal cannot avoid clarification of the problems that neuroscience has ahead of it. These problems concern: a) the way in which consciousness comes about on the basis of well-defined brain processes; b) how it represents its own organization and not a simple brain function; c) how simultaneously contains multiple distinct contents, each with its own intentionality; d) how it expresses dynamic evolutionary relations and not a set of phenomena that may be isolated; e) finally, how its order is not rigidly hierarchical, but is supported by a multiplicity of horizontal levels, each of which is in structural and functional continuum with different phenomenal events. The empirical and theoretical research effort on this topic provides an intensive contribution to the development of IC Technologies.
\end{abstract}

Index Terms - consciousness, artificial intelligence technologies, Ascending Reticular Activating System, brain imaging

Nelson Mauro Maldonato, Department of Neuroscience and Reproductive and Odontostomatological Sciences, University of Naples Federico II, Via Pansini 5, 80131, Naples, Italy (e-mail: nelsonmauro.maldonato@unina.it)

Benedetta Muzii, Department of Humanistic Studies, University of Naples Federico II, Via Porta di Massa 1, 80100, Naples, Italy (e-mail: benedetta.muzii@unina.it)

Mario Bottone, Department of Neuroscience and Reproductive and Odontostomatological Sciences, University of Naples Federico II, Via Pansini 5, 80131, Naples, Italy (e-mail: bottone.mario@fastwebnet.it)

Raffaele Sperandeo, School of Integrated Gestalt Psychotherapy - SIPGI, Via V.Veneto 240, 80058, Torre Annunziata, Italy, (e-mail: raffaele.sperandeo@gmail.com)

\section{Methodological CONTROVERSY}

$T$ HE methodology of the study of consciousness should comprise three essential aspects: 1) the search for neurophysiological correlates; 2) the causal analysis of this correlation; 3) the identification of causal links that allow a reproducibility that can confirm the explanatory hypotheses [1]. Naturally, ideal conditions of causality only exist in healthy subjects. Moreover, many structures, each with its own neurophysiological correlates, are involved in such study [2,3] and the extremely complex relations between consciousness and awareness must also be taken into account. In view of these considerations the experimental conditions for approaching an analysis of the neural correlates of consciousness appear rather complex. Although we can only access its contents through relevant verbal reports that can be shared by a third-party $[4,5]$, there are also behaviors, gestures and movements related to neural activities, which can be detected electrophysiologically or by brain imaging. In any analysis, at least three types of neural activity should be considered: one associated with conscious mental representations, one associated with sensory stimuli and one related to behavior [6]. It seems inevitable, therefore, that in the field of consciousness, more than in other scientific investigations, theory must precede and accompany experimentation. Several mechanisms and dynamics generating phenomena of variation and selection (molecular, supramolecular, cellular, cellular networks, networks of networks) are involved in generating living organisms perfectly adapted to the natural environment [7].

An elective method of study of consciousness consists of observing brain activation (PET, fMRI, MEG, event-related potentials), allowing exploration of the central nervous system before and after an adequate stimulus: the presentation of ambiguous visual stimuli, the transition from general anesthesia to awakening, the transition from the vegetative state to the

Donatella Di Corrado, Department of Sport Sciences, Kore University, Via delle Olimpiadi, 94100, Enna, Italy (e-mail:donatella.dicorrado@unikore.it)

Grazia Isabella Continisio, Continuing Medical Education Unit, School of Medicine, AOU University of Naples Federico II, Via Pansini 5, 80131, Naples, Italy (e-mail:continis@unina.it).

Teresa Rea, Department of Public Health, University of Naples Federico II, Via Pansini 5, 80131, Naples, Italy (e-mail: teresa.rea@unina.it).

Anna Esposito, Department of Psychology, University of Campania "Luigi Vanvitelli”, Viale Ellittico 31, 81100, Caserta, Italy (e-mail: iiass.annaesp@tin.it) 
minimal conscious state etc. [8]. For example, in a patient first in vegetative state, then 'minimally conscious', the resumption of the activity of the thalamus-cortical circuit at a high oscillatory frequency confirms the importance of connections between the intralaminar nuclei of thalamus and the frontal and parietal associative cortices in the maintenance of consciousness [9].

Because of its crucial evolutionary functions, consciousness cannot be restricted to a limited region of the brain. The classical studies of Moruzzi and Magoun [10] showed that the Ascending Reticular Activating System (ARAS) - a system composed by reticular formation, thalamus and thalamuscortical projection system - presides over the widespread activation of the cerebral cortex, generating the states of waking and vigilance necessary for the constitution of the contents of consciousness. However, ARAS is not restricted only to the brainstem reticular nuclei [11]. In fact, its structures project downwards to the spinal cord and upwards to the cerebral hemispheres. Furthermore, each of its constituent nuclei has particular anatomical, physiological and chemical characteristics. Circumscribing the ARAS at the midbrain level is, therefore, restrictive [12]. Many brainstem nuclei that modulate the functioning of the cortex reside in the pontine tegmentum, others in the pons and the bulb. It is also relevant that some nuclei of the brainstem go beyond the thalamus to connect directly with the fronto-basal cortex, from which diffuse bilateral projections to the cerebral cortex originate. Moreover, other nuclei go beyond both the thalamus and the fronto-basal cortex to reach wide areas of the cerebral cortex and other nuclei again are connected with the reticular nucleus of the thalamus but not with the intralaminar nuclei [13]. These factors allow us to consider the functions of ARAS as much wider and more complex than the simple 'desynchronisation' of the cerebral cortex, although the latter is essential to the state of alertness and to attention [14], while there are non-specific thalamo-cortical projections, such as the activation of the thalamo-cortical circuit at high oscillatorry frequency, fundamental for the essential functions of consciousness [15].

\section{AN ENDLESS DISPUTE}

The brain has frequently been represented as a multitude of specialized and distributed microprocessors competing with each other to access a Global Workspace for the coordination and control of information [16]. In this scenario an enormous amount of information would contribute, below the threshold of consciousness, to determining conscious subjectivity. At the foundation of this system would be the thalamocortical circuit which, with upward and downward projections, could transform the distinct contents into expressions of meaning [17]. The Global Workspace - which helps to clarify the nature of the unity of consciousness and distinguish between the conscious global workspace and unconscious levels - is constituted as a stable context-purpose within which consciousness determines its own contents among countless competitive-cooperative interactions and multiple senseperceptive sources [18]. In the second half of the 1990s, starting from experiments on vision in primates, the idea took form that at the origin of consciousness there is a system similar to the activation of neurons in layers V and VI of the cerebral cortex, mediated by thalamocortical oscillations [19]. At the origin of consciousness would be a form of neural activity of elevated visual areas that would project directly onto the prefrontal areas, creating an intermediate space of representations dislocated between a lower plane of sensations and a higher plane of cognition. Among the phenomenal and cognitive dimensions in which learning, reasoning and intelligence would take place a homunculus, in any case below the conscious level, would perceive the world through the senses, elaborating, planning and performing voluntary actions [20]. This double dimension is present in Edelman's proposed distinction between a primary consciousness (a multi-modal space that brings together different sources of information) and a higher consciousness (contemporary to the birth of language) that would allow the Self to evoke and narrate his own experiences, freeing the organism from the biological constraints of the here and now [21,22]. In this scheme, primary consciousness would connect the axiological-categorical memory to current perceptual organization, while higher consciousness would operate a synthesis between the memory of values and the memory of categories distributed in the temporal, frontal and parietal areas. From the comparison between these two types of neural organization, on one hand there is the non-Self that has sensory relationships with the world through experience, and on the other, the Self that, stimulated by social interactions, acquires rich semantics and a syntactic memory for concepts, would together constitute higher consciousness. Although Edelman [23] is willing, in his most recent works, to consider subjectivity in the conscious sphere, his general theoretical framework lacks references to external subjectivity coding and decoding messages with a symbolic alphabet. Edelman made a distinction between actual information (the number and probability of states making a difference in the Self system) and information which measures the independence of sub-sets through the bipartition of an isolated system. The complexity varies with the neuroanatomical organization: i.e. it would be minimal when the connections are statistically distributed and, instead, maximal when it is connected to defined groups of neurons. In this sense, the higher the information links between the subsets and the system, the greater the complexity. A crucial role in conscious experience would be played by an aggregate of neurons belonging to the thalamocortical system, which operates in a timespan of a hundred milliseconds in collaboration with other areas of the brain, giving origin to phenomena, with variable and dynamic spatial distributions, that are decisive for brain integration. Such integration would not be limited to the work of a subset of neurons, but would vary, from moment to moment, in the same individual and from one individual to another. Thus, it would be unified and differentiated at the same time. Fascinating though it is, this model does not make it clear how consciousness unifies such different and distant modularity [23].

Years ago, the hypothesis of the existence of a dynamic, globally integrated recruitment of representations with characteristics of unity, diversity, variability and competition in 
a circumscribed neural space was advanced [24]. According to this hypothesis, the work of a set of neurons, up to the constitution of real neural maps, connected each other over short distances (but relatively autonomous), would give rise to phenomena such as vision, language and motility. In this model long axons - particularly abundant in the cortical layers I, II and III - present in large numbers in the prefrontal cortex, dorsolateral prefrontal cortex and inferior parietal cortex. Here, a critical role is played by the frontal lobes, play a relevant role [25]. By subjecting individuals to a multimodal cognitive task (such as the Stroop test) the authors observed that the meaning of the read word was pronounced relatively automatically in accordance with the subject matter, whatever the colour of the ink, and although there was a strong inconsistency between it and the meaning of the word. The effort made in correction would indicate the recruitment of workspace neurons which, through trial and error, would control the processing of information by processors working from the bottom up. The computer simulation of the model would not only clarify the dynamics of global representation, but would be predictive of the dynamics of brain iconography during the execution of the task [26]

The ability of consciousness to integrate information raises the questions of how much a physical system can become conscious and what kind of consciousness it is endowed with. It can be presumed that part of the organization of these cortical areas is responsible for the different quality of resulting conscious experiences. According to Tononi [27, 28] the qualitative question of consciousness can be addressed as a natural extension of the quantitative (neurophysiological) problem. In other words, qualia would indicate the capacity of a system to integrate information (blue, red, etc.) due to the informational connections that bind the elements of a complex, while the types of informational relations would largely be determined by the nervous connections within (and between) each of the different cortical areas of information integration. According to Tononi, with many experimental and clinical neurobiological observations it would also be possible to measure consciousness consistently, just like physical phenomena such as entropy or temperature. According to the theory, in fact, the multiple manifestations of consciousness would be due to the modes of integration of information [28]: levels of consciousness would a be direct function of information integration and vice versa.

\section{UNITAS MULTIPLEX}

For over two centuries scholars have supported the idea of the unity (and continuity) of consciousness over time [29]. Today, instead, copious evidence shows that consciousness is a multifaceted process that simultaneously contains distinct contents, each with its own intentionality [30, 31, 32]. However, how does this internal plurality unify the different contents and the underlying biophysical-molecular mechanisms that are integrated into the experience? [33, 34]. This model has two possible variants: in the first, consciousness would be generated by a single central neural system: information would be brought to representation and then to consciousness; in the second, consciousness would emerge from the co-activation of programmed contents from distributed structures in the brain which, in a unitary process, would simultaneously process innumerable pieces of information. Yet, if the simultaneous plurality of consciousness is admitted, what is the interface and the relationship between the brain infrastructure and the activity of consciousness? In short, how is the content of the experience integrated into the brain? The distinction between a plural model and a unified theory of consciousness starts from here [35].

However, whether conscious experience is the result of the work of a central neural system, where informer content must be represented in order to be brought to consciousness, or the result of a unitary process of consciousness-creation in which the brain acts by treating many distinct pieces of information simultaneously, consciousness turns out to be a monodrome phenomenon which takes place exclusively in the brain. On the contrary, if the activity of the individual and distinct elements are generated by cerebral mechanisms distributed in the brain, then this gives rise to a plural activity of consciousness. Here, contents independent of each other and exposed to intra-sensory and intersensory influences affect each other and co-determine conscious content. In a plural model, in which the mechanisms of consciousness are multiple and localized, these interactions are perfectly constant. Ramachandran [36] has often insisted on the concrete plausibility of a model that integrates visual, auditory, tactile, proprioceptive and other experiences. These individual spheres can be altered or marginalized, relatively independently, without affecting the others [37].

Evidence on the consequences of lesions and ablation of brain areas shows that it is possible to lose the ability to visually capture motion (while preserving other aspects of visual experience) [38], and that it is possible to lose the sensation of color, while preserving the visual experience and movement. Studies on the degree and type of functional specialization and brain localization in subjects with lesion deficits have shown that the brain works on a large scale, between modes and domains that are reflected in precise anatomical districts (primary visual processing in the occipital cortex, auditory processing in the temporal cortex, design and memory processing in the frontal cortex), while precise functions are performed in well-demarcated anatomical districts and loci: for example, visual motion in V5 and color in V4. The areas of the brain that program particular information content are those in which they come to awareness. For example, different events presented simultaneously in a visual scene are not perceived with the same duration. This widespread asynchrony shows how consciousness, more than a unitary faculty, is the integrated outcome of many micro-events [32, 39]

Yet, if consciousness has this plural nature, why do we perceive ourselves as unitary subjects? And how does the Self emerge from such multiplicity? One could discuss the meaning of the unitary subject and its inner core that we define as Self at length. Without getting into such controversial territory [40], one could say that the Self emerges when the individual events produced by the brain obtain a sufficiently representative, 
coherent and cohesive form [41]. Under normal circumstances, we experience a structured world of distinct and ordered objects in space within significant spatial-temporal patterns, organized according to regularity and extramodal (colour, shape, etc.) and intramodal (proprioceptive, auditory and visual) content. In reality, representative cohesion is not an invariant feature of conscious experience, but the outcome of a selection through which the brain seeks a path towards its own integration. Thus, the appearance of the Self has to do with an ordering activity of consciousness, which elaborates and sustains this multiplicity of local contents generated by conscious experience, in relation to one another.

A plural model of consciousness could explain the birth of the Self, with a space of centrencephalic functional integration $[15,42,43]$ that supports both integration and global communication at its base. Consciousness would thus appear as a multiple unity rather than an undifferentiated unity. Let us be clear: the unification of consciousness is not a matter of uniqueness, but of representative cohesion: a cohesion plausibly operated by cortico-cortical circuits, and one that would explain how a Self emerges from the multiple representative activities of the brain. All conscious experiences are, in fact, unified within a conscious field [44] Hence, unity is implicit in qualitative subjectivity. But if our awareness is determined by infinite parts, what we perceive is not just one subject with different states of consciousness, but many different fields of unified consciousness. In other words, the unity of awareness follows subjectivity and quality, because there is no way to have subjectivity and quality without unity.

It can never be stressed enough that there is a need to distinguish instantaneous unity from the organized unification of conscious sequences that we obtain, for example, from iconic memory [1]. For non-pathological forms of consciousness and memory it is essential that the conscious sequence is organized in a certain order [45]. For example, comprehension of a sentence is determined by the ability to remember its beginning through its duration and to reach its end producing a coherent discourse [46]. Now, if instantaneous unity is part of the definition of consciousness, then unity organized through time (duration) is essential to consciousness, even if it is not necessary for the existence of conscious subjectivity.

\section{CONCLUSION}

Despite the prodigious advances in neuroscientific research, the problem of consciousness remains an unsolved mystery. In the history of science, it has often been the case that a solution to a problem raises new questions. This also applies to the consciousness. The more we learn about it, the more we need specific, articulate and refined answers and knowledge about what we do not know yet. In this sense, achieving an adequate understanding of consciousness in all its aspects will require many other developments, both theoretical and experimental [47]. In this paper, for example, we could not consider important distinctions such as between primary consciousness and self-consciousness, nor the close relationship between consciousness and memory or between consciousness and language. We have not even mentioned the great practical difficulties that hinder the measurement of the ability to integrate information in a living brain. Nor has it been possible here to consider the many implications of the equivalence between consciousness and the ability to integrate information. Although it has been on the confines of scientific debate for almost a century, the literature on consciousness is growing day by day with the contributions of thinkers and researchers from different disciplines [48]. So far, the Galilean categories have allowed us great success in the explanation of physical phenomena, but they have proved insufficient so far for understanding the nature of consciousness. No one knows how a physical system (the brain, the nervous system, a set of neurons) is able to generate conscious experience. The brain is, like so many things, a physical object, but we are unable to explain how a certain system can produce conscious experience, whether there is a specific element that gives rise to consciousness, and whether it develops suddenly or gradually. Now, if neuroscience is unable to answer any of these questions, could the way forward be to address the issue through the construction of organisms with "artificial consciousness" [49]? Would it be ethically implausible to try to understand consciousness through refined forms of artificial intelligence?

At the beginning of the third millennium, the decisive turning point in human history - the understanding of consciousness could be achieved through AI [50]. So far, along with other essential elements, there has been insufficient technological know-how to build an artificial conscious entity, but now that robots are starting to look like human beings - both in terms of computing power and physical structure - the solution may be closer. According to some thinkers, within a few decades the construction of super-intelligent machines will allow us to transcend the human condition $[51,52]$. The use of nanorobotic systems will help us to generate creative ideas, to think independently, to expand our memory systems, probably connecting our minds to the cloud, the great and potentially infinite archive of information stored on the Internet [53]. Our very way of thinking will become a hybrid expression of biological and non-biological elements. As the cloud gets more sophisticated, we shall probably update ourselves. With time, the role of non-biological consciousness will become more and more important and, as a result, our way of thinking will become more and more non-biological. Once this level is reached, it is reasonable to think that there will be positive effects in the development of AI-driven devices, which will generate more and more powerful and sophisticated AI [54, 55, 56]. In this sense, the Subsumption architecture model by Brooks takes on interest: it is a control architecture, conceived in opposition to the traditional AI. According to this model, the behaviour of robots can be oriented through symbolic mental representations of the world, combining sensory information with the selection of the action in an intimate and bottom-up way [57]. According to Brooks, the construction of an embodied agent is articulated on different levels: a) an integrated physical control system; b) an internal relation of the behavioral layers directly rooted in the world percieved by robots; c) the interaction of these modules, which generates 
emerging properties based on the information of the senses. According to Brooks, the construction of an embodied agent is articulated on different levels: a) an integrated physical control system; b) an internal relation of the behavioral layers directly rooted in the world that the robot perceives; c) the interaction of these modules, which generates emerging properties according to an embodied model [58].

As far as the acquisition of new skills through self-learning is concerned, it cannot be excluded that a brain capable of extraordinary calculations may make the development of a new and more powerful sensory sphere possible, even if it will be very difficult to replicate the intricate work done by the longtried adaptive process of the species and to define the sophisticated processing of information as emotions such as pain or pleasure. But it is not at all senseless to think that the speed of technological change will produce such an impact that it will profoundly change human life $[59,60]$ and lead to a real discontinuity in the network of human history created by evolution $[61,62]$.

\section{REFERENCES}

[1] A. D. Di Sarno et al., "Conscious experience using the Virtual Reality: A proposal of study about connection between memory and conscience" in 2018 9th IEEE CogInfoCom, Budapest, Hungary, 2018, pp. 000289-000294, Dor: 10.1109/CogInfoCom.2018.8639966.

[2] A. Nani et al., "The Neural Correlates of Consciousness and Attention: Two Sister Processes of the Brain", Frontiers in Neuroscience, vol.13, pp.1196, Oct. 2019, Dor: 10.3389/fnins.2019.01169.

[3] N. M. Maldonato, S. Dell'Orco, M. Springer, "Rethinking Consciousness: Some Hypothesis on the Role of the Ascending Reticular Activating System in the Global Workspace" in Frontiers in Artificial Intelligence and Applications. Vol.234, IOS Press, Amsterdam, 2011, pp. 212-219.

[4] J.L. Díaz, "A narrative method for consciousness research", Frontiers in Neuroscience, vol.7, pp.739, Nov. 2013, DOI: 10.3389/fnhum.2013.00739.

[5] M. Tsikandilakis, P. Bali, J. Derfuss, P. Chapman, "The unconscious mind: From classical theoretical controversy to controversial contemporary research and a practical illustration of the "error of our ways"”, Consciousness and Cognition, vol.74, Sep. 2019, DoI: $10.1016 / \mathrm{j} . \operatorname{con} \operatorname{cog} .2019 .102771$

[6] C. Farrer, C.D. Frith, "Experiencing Oneself vs Another Person as Being the Cause of an Action: The Neural Correlates of the Experience of Agency", Neuroimage, vol.15, 3, pp. 596-603, Mar. 2002, Dor: $10.1006 /$ nimg.2001.1009.

[7] G. A. Mashour, M. T. Alkire, "Evolution of consciousness", Proceedings of the National Academy of Sciences of the United States of America, vol.110 Suppl 2, 2013, pp. 10357-10364, DOI: $10.1073 /$ pnas.1301188110.

[8] B. Kotchoubey, "Event-related potentials predict the outcome of the vegetative state", Clinical Neurophysiology, vol.118, 3, pp. 477-479, Mar. 2007, DoI: 10.1016/j.clinph.2006.11.018

[9] Y. B. Saalmann, "Intralaminar and medial thalamic influence on cortical synchrony, information transmission and cognition", Frontiers in Systems Neuroscience, vol.8, May 2014, 83, DoI: $10.3389 /$ fnsys.2014.00083.

[10] G. Moruzzi, H. W. Magoun, "Brain stem reticular formation and activation of the EEG", Electroencephalography and Clinical Neurophysiology, vol.1, 1-4, pp. 455-473, 1949, DOI: $10.1016 / 0013-4694(49) 90219-9$.

[11] N. D. Schiff, F. Plum, "The Role of Arousal and "Gating" Systems in the Neurology of Impaired Consciousness", Journal of Clinical Neurophysiology, vol.7, 5, pp. 438-452, Sep. 2000, DoI: 10.1097/00004691-200009000-00002.
[12] N. M. Maldonato, "The Ascending Reticular Activating System: The common root of consciousness and attention", in Recent Advances of Neural Network Models and Applications. Smart Innovation, Systems and Technologies, vol.26, pp. 333-344, Switzerland, Springer Nature, 2014, DoI: 10.1007/978-3-319-04129-2_33.

[13] J. L. Lanciego, N. Luquin, J. A. Obeso (2012). "Functional neuroanatomy of the basal ganglia", Cold Spring Harbor perspectives in medicine, vol.2, 12, Dec. 2012, a009621, Dor: 10.1101/cshperspect.a009621.

[14] N. M. Maldonato et al., "Exploring the Relationship Between Attention and Awareness. Neurophenomenology of the Centroencephalic Space of Functional Integration" in Neural Approaches to Dynamics of Signal Exchanges. Smart Innovation, Systems and Technologies, vol.151, Springer, Singapore, 2020, pp. 495-501, Dor: 10.1007/978-981-13-8950-4_44.

[15] N. M. Maldonato, A. Esposito, S. Dell'Orco, "Consciousness and the Archipelago of Functional Integration: On the Relation Between the Midbrain and the Ascending Reticular Activating System", in Quantifying and Processing Biomedical and Behavioral Signals. Smart Innovation, Systems and Technologies, vol.103, pp- 127-133, Switzerland, Springer Nature, 2019, DoI: $10.1007 / 978-3-319-95095-2 \quad 12$

[16] B. J. Baars, A. Alonzi, "The global workspace theory", in The Routledge Handbook of Consciousness, 1st ed. New York, USA, Routledge, 2018, pp. 122-136.

[17] N. M. Maldonato, "From neuron to consciousness: For an experiencebased neuroscience", World Futures, vol.65, 2, pp. 80-93, 2009, DoI: $10.1080 / 02604020802594857$.

[18] R. Prakash et al., "Global workspace model of consciousness and its electromagnetic correlate", Annals of Indian Academy of Neurology, vol.11, pp.146-153, Jul. 2008, Dor: 10.4103/0972-2327.42933.

[19] R. Llinás, U. Ribary, D. Contreras, C. Pedroarena, "The neuronal basis for consciousness", Philosophical Transactions of the Royal Society B: Biological Sciences, vol.353, 1377, pp. 1841-1849, Nov. 1998, Dor: 10.1098/rstb.1998.0336.

[20] N. M. Maldonato et al., "The Unaware Brain: The Role of the Interconnected Modal Matrices in the Centrencephalic Space of Functional Integration" in Neural Approaches to Dynamics of Signal Exchanges. Smart Innovation, Systems and Technologies, vol.151, Springer, Singapore, 2020, pp. 513-521, DOI: 10.1007/978-981-13-8950-4_46

[21] G. M. Edelman, J. A. Gally, B. J. Baars, "Biology of consciousness", Frontiers in Psychology, vol.2, 4, Jan. 2011, DoI: $10.3389 /$ fpsyg. 2011.00004 .

[22] N. M. Maldonato, "The birth of consciousness: The origin of temporality and the sense of self", Human Evolution, vol.28, 1-2, pp. 1-11, 2013.

[23] G. M.Edelman, "Second nature: Brain science and human knowledge", 1st ed., Yale University Press, 2007, pp. 1-203.

[24] S. Dehaene, J. P. Changeux, J. P. Nadal, "Neural networks that learn temporal sequences by selection", Proceedings of the National Academy of Sciences, vol.84, pp. 2727-2731 May 1987, DoI: $10.1073 /$ pnas.84.9.2727.

[25] S. Dehaene, M. Kerszberg, J. P. Changeux, "A neuronal model of a global workspace in effortful cognitive tasks", Proceedings of the National Academy of Sciences of the United States of America, vol.95, pp. 14529-14534, Nov. 1998, Dor: 10.1073/pnas.95.24.14529.

[26] M. Farisco, J. H. Kotaleski, K. Evers, "Large-scale brain simulation and disorders of consciousness. Mapping technical and conceptual issues", Frontiers in Psychology, vol.9, Apr. 2018, DOI: 10.3389 /fpsyg.2018.00585.

[27] G. Tononi "An information integration theory of consciousness" $B M C$ Neuroscience, vol.5, Nov. 2004, Dor: 10.1186/1471-2202-5-42.

[28] G. Tononi "Consciousness as integrated information: A provisional manifesto" Biological Bulletin, vol.215, pp. 216-242, Dec. 2008, Dor: $10.2307 / 25470707$.

[29] T. Bayne, "The Unity of Consciousness", University of Oxford, United Kingdom, 2011, Dor: 10.1093/acprof:oso/9780199215386.001.0001.

[30] T. Bayne, A. K. Seth, M. Massimini, "Are There Islands of Awareness?", Trends in Neurosciences, vol.43, 1, pp. 6-16, Jan. 2020 DoI: $10.1016 /$ j.tins.2019.11.003. 
[31] W. Wiese, "How to solve the problem of phenomenal unity: finding alternatives to the single state conception", Phenomenology and the Cognitive sciences, vol.16, 5, pp.811-836, Dec. 2017 DOI: $10.1007 / \mathrm{s} 11097-016-9478-7$

[32] S.Zeki, "The disunity of consciousness" Trends in Cognitive sciences, vol.7, 5, pp. 214-218, May 2003 DoI: $10.1016 / \mathrm{S} 1364-6613(03) 00081-0$

[33] N. Humphrey, "How to solve the mind-body problem", Journal of Consciousness Studies, vol.7, 4, pp. 5-20, 2000.

[34] N. Humphrey, "Easy does it: A soft landing for consciousness", Journal of Consciousness Studies, vol.26, 9-10, pp. 105-114, 2019

[35] N. M. Maldonato, S. Dell'Orco, "Naturalizing consciousness", Human Evolution, vol.25, 3-4, pp. 213-220, Jul. 2010.

[36] V. S. Ramachandran, "Consciousness and body image: Lessons from phantom limbs, Capgras syndrome and pain asymbolia", Philosophical Transactions of the Royal Society B: Biological Sciences, vol.353, pp.1851-1859, Nov. 1998, DoI: 10.1098/rstb.1998.0337.

[37] N. M. Maldonato et al., "Mind, brain and altered states of consciousness", Acta Medica Mediterranea, vol.34,2, pp. 357-366, 2018 DOI: 10.19193/0393-6384_2018_2_56.

[38] S. Zeki, A. Bartels, "The asynchrony of consciousness", Proceedings of the Royal Society B: Biological Sciences, vol.265, pp. 1583-1585, Aug. 1998, DoI: 10.1098/rspb.1998.0475.

[39] A. G. Casali et al. "A theoretically based index of consciousness independent of sensory processing and behavior", Science Translation Medicine, vol.5, Aug. 2013, DoI: 10.1126/scitranslmed.3006294.

[40] A. D. Di Sarno et al. "To the Roots of the Sense of Self: Proposals for a Study on the Emergence of Body Awareness in Early Infancy Through a Deep Learning Method" in Neural Approaches to Dynamics of Signal Exchanges. Smart Innovation, Systems and Technologies, vol.151, Springer, Singapore, 2020, pp. 415-429, DoI: 10.1007/978-981-13-8950-4_37.

[41] O. Blake, "Multisensory brain mechanisms of bodily selfconsciousness", Nature Reviews Neuroscience, vol.3, pp.556-571, Aug. 2012, DoI: 10.1038/nrn3292.

[42] R. Sperandeo, E. Moretto, G. Baldo, S. Dell'Orco, N. M. Maldonato, "Executive functions and personality features: A circular interpretative paradigm" 8th IEEE International Conference on Cognitive Infocommunications (CogInfoCom), Dec. 2017, pp. 000063169184000066, Dor: 10.1109/CogInfoCom.2017.8268217.

[43] N. M. Maldonato, R. Sperandeo, P. Valerio, M. Duval, C. Scandurra, S. Dell'Orco, "The centrencephalic space of functional integration: A model for complex intelligent systems", Acta Polytechnica Hungarica, vol.15, 5, pp. 169-184, 2018, DoI: 10.12700/APH.15.5.2018.5.10.

[44] B. Libet, J. R. Searle, "Consciousness, free action and the brain", Journal of Consciousness Studies, vol.8, 8, pp. 59-65, 2001.

[45] C. Repetto, S. Serino, N. M. Maldonato, T. Longobardi, R. Sperandeo, D. Iennaco, G. Riva, "Immersive episodic memory assessment with $360^{\circ}$ videos: The protocol and a case study", Lecture Notes of the Institute for Computer Sciences, Social-Informatics and Telecommunications Engineering, LNICST, vol.288, pp. 117-128, 2018, DoI: 10.1007/978-3-030-25872-6_9.

[46] V. Mongelli, E. L. Meijs, S. van Gaal, P. Hagoort, "No language unification without neural feedback: How awareness affects sentence processing", NeuroImange, vol.202, Nov. 2019, DoI: 10.1016/j.neuroimage.2019.116063.

[47] B. Kotchoubey et al. "Methodological Problems on the Way to Integrative Human Neuroscience", Frontiers in Integrative Neuroscience, vol.10, Nov. 2016, Dor: 10.3389/fnint.2016.00041.

[48] M. Overgaard, "The Status and Future of Consciousness Research", Frontiers in Psychology, vol.8, Oct. 2017, DoI: $10.3389 /$ fpsyg. 2017.01719 .

[49] N. M. Maldonato, S. Dell'Orco, "Adaptive and evolutive algorithms: A natural logic for artificial mind", Intelligent Systems Reference Library, vol.106, pp. 13-21, 2016, DOI: $10.1007 / 978-3-319-31053-4 \_3$.

[50] A. Esposito et al. "Some Note on Artificial Intelligence", Neural Approaches to Dynamics of Signal Exchanges. Smart Innovation, Systems and Technologies, vol.151, Springer, Singapore, 2020, pp. 3-8, DOI: 10.1007/978-981-13-8950-4_1.
[51] D. Silichev, A. Volobuev, E. Kuzina, "Artificial Intelligence and the Future of the Mankind", in Ubiquitous Computing and the Internet of Things: Prerequisites for the Development of ICT. Studies in Computational Intelligence, vol.826. Springer, 2019, pp. 699-706, DOI: 10.1007/978-3-030-13397-9_74.

[52] N. M. Maldonato, S. Dell'Orco, "Toward an evolutionary theory of rationality", World Futures: Journal of General Evolution, vol.66, pp. 103-123, 2010, DoI: 10.1080/02604020903510257.

[53] S. M. Platek, A. Hasicic, A. L. Krill, "Boldly going where no brain has gone: Futures of evolutionary cognitive neuroscience", Future of Evolutionary Psychology, vol.43, pp. 771-776, Oct. 2011, DOI: 10.1016/j.futures.2011.05.020.

[54] N. M. Maldonato, I. Anzoise, "Homo-Machina Visual Metaphors, Representations of Consciousness and Scientific Thinking" in Neural Nets and Surroundings. Smart Innovation, Systems and Technologies, vol.19, Springer, Berlin, Heidelberg 2013, pp. 437-451, DoI: $10.1007 / 978-3-642-35467-043$.

[55] A. Esposito, S. Basis, F. C. Morabito, E. Pasero, "Some notes on computational and theoretical issues in artificial intelligence and machine learning" in Advances in Neural Networks. WIRN 2015. Smart Innovation, Systems and Technologies, vol.54, Springer, 2016, pp. 3-12, DoI: 10.1007/978-3-319-33747-0_1.

[56] P. Baranyi, A. Csapo, "Cognitive Infocommunications: CogInfoCom", 11th IEEE International Symposium on Computational Intelligence and Informatics, Budapest, Hungary, 2010, DOI: 10.1109/CINTI.2010.5672257.

[57] R. A. Brooks, "Intelligence Without Representation", Artificial Intelligence vol.47, 1-3, pp. 139-159, 1991a DoI: 10.1016/0004-3702(91)90053-M

[58] R. A. Brooks "Intelligence Without Reason" In: Proceedings of the Twelfth International Joint Conference on Artificial Intelligence (IJCAI-91), 1991b, pp. 569-595, Sydney, Australia, http://hdl.handle.net/1721.1/6569

[59] A. Esposito et al. "Seniors' Appreciation of Humanoid Robots", in Neural Approaches to Dynamics of Signal Exchanges. Smart Innovation, Systems and Technologies, vol.151, Springer, Singapore, 2020, pp. 331-345, DOI: 10.1007/978-981-13-8950-4_30.

[60] P. Baranyi, A. Csapo, "Definition and Synergies of Cognitive Infocommunications", Acta Polytechnica Hungarica, vol. 9, 1, pp. 67$83,2012$.

[61] N. M. Maldonato, P. Valerio, "Artificial Entities or Moral Agents? How AI is Changing Human Evolution", in Multidisciplinary Approaches to Neural Computing. Smart Innovation, Systems and Technologie, vol.69, Springer, 2017, pp. 379-388, DoI: 10.1007/978-3-319-56904-8_36.

[62] D. Vernon, G. Metta, G. Sandini, "A Survey of Artificial Cognitive Systems", IEEE Transactions on Evolutionary Computation, vol.11, 2, pp. 151-179, 2007, DoI: 10.1109/TEVC.2006.890274.

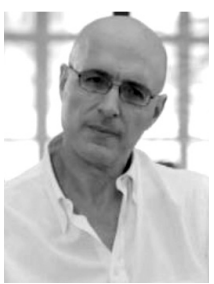

Nelson Mauro Maldonato is a psychiatrist and professor of Clinical Psychology at the Department of Neuroscience, Reproductive Sciences and Odontostomatology of the University of Naples Federico II, where he lead the Institute of Clinical Psychology. He has been a recurrent visiting professor at the Universidade de São Paulo and Pontifícia Universidade Católica (Brasil) of São Paulo and Duke University (Usa). He is the author of almost 400 scientific papers translated into several languages. $\mathrm{He}$ has given over 300 lectures, most of them as invited speakers abroad. In his career he has received 6 international awards. Also, he is the Scientific Director of the Settimana Internazionale della Ricerca. His current research interests include consciousness disorders, personality disorders, neurobiological bases of improvisation, artificial intelligence and consciousness. 


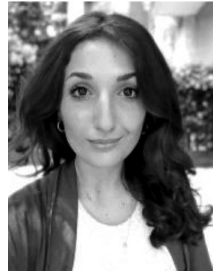

Benedetta Muzii received the M.S. degree in Psychology from the University of Naples Federico II, Naples, in 2016.

She is currently pursuing the Ph.D. degree in Mind, Gender and Languages at University of Naples Federico II, Italy.

From 2018 to 2019 , she was research assistant with the Institute of Clinical Psychology at the Department of Neuroscience, University of Naples Federico II. Her research interest includes the field of Clinical Psychology, in particular the assessment of personality dimensions and health outcomes in medicine and surgery interventions.

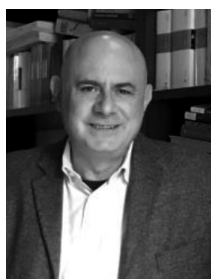

Mario Bottone graduated in Philosophy at the Faculty of Letters and Philosophy of the University of Naples "Federico II" in 1989.

He also pursued his M.S. degree in Psychology at the University of Rome "La Sapienza" in 1996. He specialized in Life Cycle Psychology at the Faculty of Letters and Philosophy of the University of Naples "Federico II" in 1999. In 2004 he obtained the Ph.D. degree in Health Psychology and Prevention of Individual and Social Risk, obtained at the Department of Relational Sciences "G. Iacono" of the Faculty of Letters and Philosophy of the University of Naples "Federico II". Since 2006 he is a researcher in Clinical Psychology at the Faculty of Medicine and Surgery of the University of Naples "Federico II". He is a lincesed clinical psychologist and psychotherapist at the DAI of the University Hospital of "Federico II". His research interests pertain clinical psychopathology and consciousness disorders.

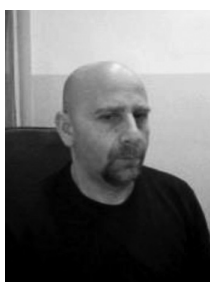

Raffaele Sperandeo graduated in Medicine in 1991, and he is a specialized physician in Psychiatry. He pursued the specialization Gestalt Psychotherapy in 1996. In 2001 he obtained the Ph.D. degree in Behavioral Sciences. He is contract professor at the University of Basilicata and at the University of Naples "Federico II" and director of the School of Specialization in Integrated Gestalt Psychotherapy.

He has published more than 40 scientific articles in national and international scientific journals, has presented 60 papers at national and international congresses and has written numerous book chapters. He has directed and participated in the scientific committees of numerous national and international congresses

His main research topic is related to psychopathology, treatment of personality disorders and the application of statistical methods and artificial intelligence technologies in this field.

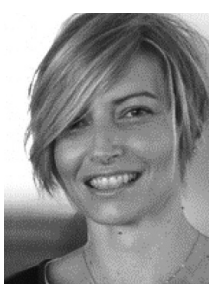

Donatella Di Corrado graduated in Philosophy in Catania on 1999 with honors. She obtained a six-month Scholarship in the disciplinary sector "Historical, Philosophical, Pedagogical and Psychological Sciences", to attend $\mathrm{Ph} . \mathrm{D}$. courses at foreign institutions of higher education in the U.S.A. (2000-2001). She attended the Institute Ramapo College of New Jersey, the Institute of Psychology (Keene State College) and the Department of Psychology at Stanford University, California in collaboration with Professor Albert Bandura. She conducted research at the Institute of Medical Therapy and the Institute of Gynecology, University of Catania.

In February 2006 she obtained the Ph.D. degree in Sport Sciences at the Faculty of Medicine, University of Catania.

In 2018 she became Associate Professor for the scientific-disciplinary sector M-EDF/01 "Methods and teaching of motor activities", University Kore of Enna. Her research activity concerns mood, imagery, human perception, emotions, health, and attention in sport.

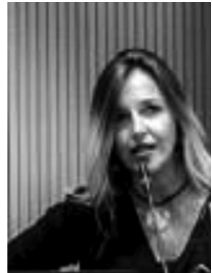

Grazia Isabella Continisio graduated in Psychology at the Second University of Naples. She is a licensed clinical psychologist, systemic-relational and family psychotherapist. She is Responsible of Continuing Medical Education Unit of Medical School, University of Naples Federico II. Her research interests include developmental and educational psychology and their impact in chronic diseases in childhood and adolescence; narrative based medicine as medical approach aimed to address the relational and psychological dimensions that occur with physical illness, with an attempt to deal with the individual stories of patients and even though the healthcare professionals; neonatal screening for hearing problems, assessment of psychomotor development of deaf children and dialogic reading in the rehabilitation of children with hearing loss; HIV desease and stigma.

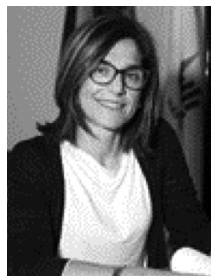

Teresa Rea received B.S. degree in Nursing Sciences from the Second University of Naples in 1995, M.S degree in Nursing from the Università degli Studi di Roma "Tor Vergata", Rome, 2002, Master in Territorial Nursing and Public Health from the University Federico II of Naples in 2005, MS degree in Nursing and Midwifery Sciences from the University Federico II of Naples in 2007, and the Ph.D. degree in Management of Companies and Healthcare Organizations from the University Federico II of Naples in 2016. From 2003 she is adjunct professor in Nursing at University Federico II of Naples. From 2011 she coordinates the teaching activities of the degree courses and of the Master's Degree in Nursing and Obstetric Sciences at the Department of Public Health, University Federico II of Naples. She is author of 33 articles. Her research interests include Nursing management, Critical Care, Nursing Education. Also, she is Editor in Chief of the journal NSC Nursing.

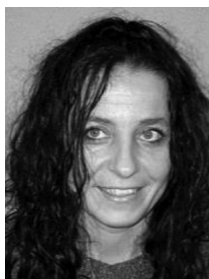

Anna Esposito received her degree in Information Technology and Computer Science in 1991 at the Salerno University, and the Ph.D. degree in Applied Mathematics and Computer Science at the University of Naples "Federico II" with a thesis developed at MIT, RLE (Cambridge, USA) in 1995. From November 2000 to December 2002 she got a position as Research Professor in the Department of Computer Science and Engineering at Wright State University, Dayton, $\mathrm{OH}$ USA to which she currently collaborate as research affiliate. She currently is Associate Professor in Computer Science at Università della Campania "Luigi Vanvitelli" and director of the BeCogSys lab. She is author of more than 240 peer reviewed publications and editor/co-editor of over 30 international books. 